\title{
OPTIMIZATION OF DRUG SOLUBILITY USING ASPEN PLUS: ACETYLSALICYLIC ACID (ASPIRIN) SOLUBILITY - A SECOND CASE STUDY
}

\author{
KAMAL I AL-MALAH* \\ Department of Chemical Engineering, Higher Colleges of Technology, Ruwais, Abu-Dhabi, UAE. \\ Email: almalak61@hotmail.com
}

Received: 19 February 2019, Revised and Accepted: 17 March 2020

\section{ABSTRACT}

Objective: The objective of the study is to optimize the solubility of a drug or a drug-like molecule using Aspen Plus simulation platform. Aspirin (solute) was taken as the second case study. The following solvents were used in our dry (virtual) laboratory experiment: Water, acetone, ethanol, and ethylene-glycol-mono-propyl-ether (PROPGLYC).

Methods: A simplified process flow sheet made of a single mixing tank where it has five feed streams, representing the solute, the water, and the set of three organic solvents, and one product stream where aspirin is either solubilized (liquid solution) or remains as solid crystal. Minimization of the molar Gibbs free energy of mixing, $\Delta \mathrm{G}_{\text {mix }}$, was used as an objective function from an optimization point of view. The Non-random Two-liquid (NRTL) property method was used to analyze the solution properties.

Results: Using the molar Gibbs free energy of mixing, $\Delta \mathrm{G}_{\text {mix }}$ as a criterion of solution thermodynamic stability, it was found that the most stable solution is the quinary mixture made of $24.42 \%$ aspirin, $10.22 \%$ water, $21.08 \%$ acetone, $19.51 \%$ ethanol, and 24.77 mole $\%$ PROPGLYC.

Conclusions: Exploiting Aspen Plus can be extended to handle the solubility of a new drug-like molecule once it is defined within its molecular editor with a little knowledge such as density and/or melting point.

Keywords: Solubility, Acetylsalicylic acid, Aspen plus, Optimization, Aspirin, Gibbs free energy.

(c) 2020 The Authors. Published by Innovare Academic Sciences Pvt Ltd. This is an open access article under the CC BY license (http://creativecommons. org/licenses/by/4. 0/) DOI: http://dx.doi.org/10.22159/ajpcr.2020.v13i4.37143

\section{INTRODUCTION}

0-Acetylsalicylic acid, 2-Acetoxybenzoic acid, or aspirin, with the linear formula (2- $\left.\left(\mathrm{CH}_{3} \mathrm{CO}_{2}\right)-\mathrm{C}_{6} \mathrm{H}_{4}-\mathrm{CO}_{2} \mathrm{H}\right)$, belongs to the family of medications called analgesics (pain relievers), antipyretics (fever reducers), antiinflammatories (inflammation reducers), and platelet aggregation inhibitors (anti-clotting agents). It has a limited solubility in water, which amounts to $2-4 \mathrm{mg} / \mathrm{mL}$ and its solubility varies significantly with temperature [1]. Aspirin is more soluble in ethanol, ethyl ether, chloroform, sodium hydroxide solution, and sodium carbonate solution than in water.

Maia and Giulietti [2] examined the solubility of acetylsalicylic acid in ethanol, acetone, propylene glycol, and 2-propanol, in addition to comparing their solubility values with the expected from an ideal solution. The solubility of acetylsalicylic acid was found to be highest in acetone in all studied temperature ranges until $\mathrm{T}=326.3 \mathrm{~K}$. Propylene glycol was found to have lower solubility data in all studied temperature ranges. The solvent that presented the lowest average percentage logarithmic deviation, concerning the ideality of the system, was ethanol, and the highest value of average percentage logarithmic deviation was found in propylene glycol solutions. They also contrasted their experimental solubility data versus those predicted by the Nývlt model and found that the Nývlt model was capable of properly representing the experimental data.

Huang et al. [3] examined the introduction of polar cosolvents to dramatically increase solubilities of polar organic solids in supercritical $\mathrm{CO}_{2}$. In their study, they have measured the solubility of aspirin in methanol-modified and ethanol-modified supercritical $\mathrm{CO}_{2}$ by means of a dynamic saturation method. Experimental results showed that the aspirin solubility could be greatly enhanced up to 14 times by introducing 3.0 mole \% methanol or ethanol. In their opinion, the enhancement was mainly attributed to the strong attractive molecular interactions between the polar cosolvent and the polar solute. The aspirin ternary solubility data were fairly well described using the Peng-Robinson equation of state (EoS) model with an absolute average relative deviation ranging from 14 to $23 \%$.

Mota et al. [4] examined the solubility of drug-like molecules in pure organic solvents using the cubic-plus-association EoS that combines the simplicity and robustness of a cubic EoS with the Wertheim's association contribution. In their work, such an EoS was proposed for the $1^{\text {st }}$ time to model organic phase solubilities of drug-like molecules in a wide range of temperatures. They estimated solubilities of acetanilide, acetylsalicylic acid, adipic acid, ascorbic acid, hydroquinone, ibuprofen, paracetamol, and stearic acid in alcohols, ketones, alkanes, esters, acids, aromatics, chlorinated solvents, as well as in other common solvents. They accounted for hydrogen-bonding behavior for each associating group being treated individually as well as multiple group substitutions. Accurate correlations were obtained using a single binary interaction parameter with an average absolute deviation of $24.2 \%$.

In the previous works, the aqueous solubility of simple inorganic [5] and that of simple (single carbon) organic [6] molecules were examined and expressed in terms of important molecular properties. Moreover, the aqueous solubility of some organic solvents was examined as a function of some selected molecular descriptors which are thought to affect the solvation process. It was found that to have an organic solvent with a high aqueous solubility, it has to have a low value of both the log partition coefficient between octanol and water, LogKow, and the molecular rugosity, $\mathrm{R}=\mathrm{V} / \mathrm{S}$, accompanied by a high value of polar to hydrophobic surface area ratio, PHSAR [7]. Aspen Plus was used to optimize acetaminophen (paracetamol) solubility in a set of solvents, including water [8]. Three objective functions were used to find the 
optimum formulation in terms of molar and mass composition of paracetamol solution.

In this work, aspirin, also known as o-acetylsalicylic acid, 2-acetoxybenzoic acid, is used as a solid solute to demonstrate how we can exploit Aspen Plus simulator as a powerful tool to optimize the solubility of aspirin using different organic solvents and water, as well. The minimization of molar Gibbs free energy of mixing ( $\Delta \mathrm{Gmix}$ ), expressed in $\mathrm{kJ} / \mathrm{kmol}$, is used as the objective function, from an optimization standpoint.

\section{METHODS}

The following paragraph describes what Aspen Plus simulator is all about: "Aspen Plus, a flow sheet simulation, is a computer software that is used to quantitatively model a chemical processing plant, which in addition to the core reactor unit, it also includes pre-treatment and posttreatment steps, as well. Thus, simulation of an entire chemical process, starting from the raw material side down all the way to the final, finished product side, is symbolically represented by different icons where each icon stands for a unit operation, chemical process, input/output material stream, input/output energy stream, or input/output electric/pneumatic

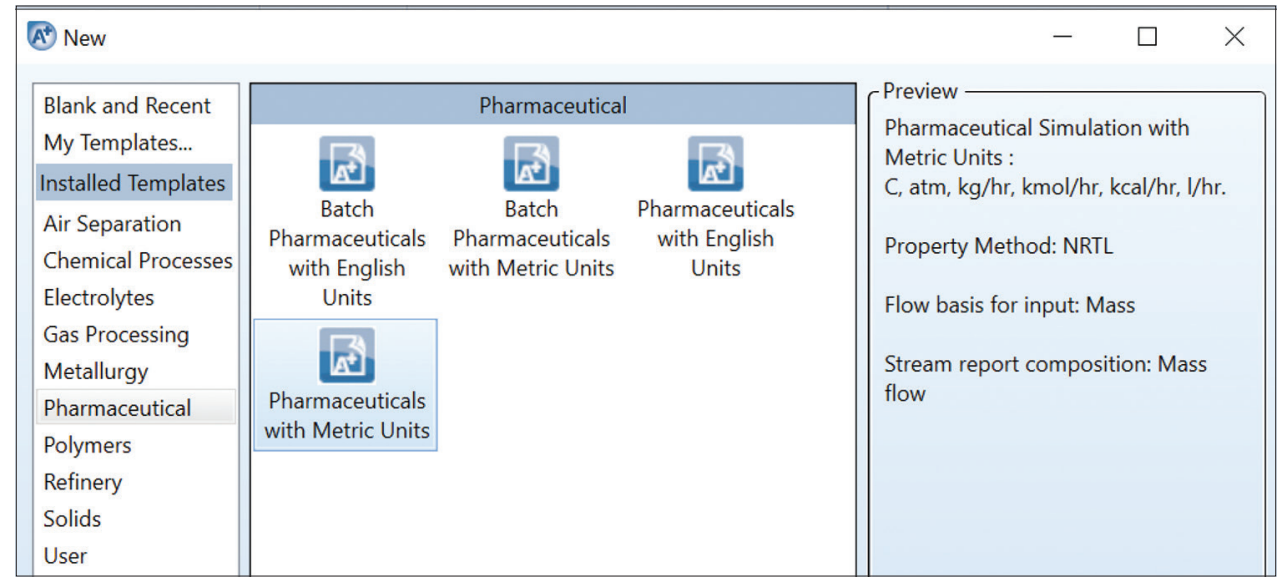

Fig. 1: Selection of the pharmaceutical template to suit the components under study

\begin{tabular}{|c|c|c|c|c|c|c|}
\hline \multicolumn{7}{|c|}{ Components $x+$} \\
\hline \multicolumn{2}{|c|}{ OSelection } & Petroleum & $\mathrm{n}$ Nonconventional & Enterprise Database & Comments & \\
\hline \multicolumn{7}{|c|}{ Select components } \\
\hline 4 & \multicolumn{2}{|c|}{ Component ID } & \multicolumn{2}{|c|}{ Type } & Component name & Alias \\
\hline$>$ & \multicolumn{2}{|c|}{ ASPIRIN } & \multicolumn{2}{|l|}{ Conventional } & ACETYLSALICYLIC-ACID & $\mathrm{C} 9 \mathrm{H} 8 \mathrm{O} 4$ \\
\hline$>$ & \multicolumn{2}{|l|}{ WATER } & \multicolumn{2}{|l|}{ Conventional } & WATER & $\mathrm{H} 2 \mathrm{O}$ \\
\hline$>$ & \multicolumn{2}{|c|}{ ACETONE } & \multicolumn{2}{|l|}{ Conventional } & ACETONE & Сзн60-1 \\
\hline$>$ & \multicolumn{2}{|c|}{ ETHANOL } & \multicolumn{2}{|l|}{ Conventional } & ETHANOL & $\mathrm{C} 2 \mathrm{H} 6 \mathrm{O}-2$ \\
\hline$>$ & \multicolumn{2}{|c|}{ PROPGLYC } & \multicolumn{2}{|l|}{ Conventional } & ETHYLENE-GLYCOL-MONOPR... & C5H12O2-D3 \\
\hline \multicolumn{3}{|l|}{$>$} & & & & \\
\hline & Find & Elec $\mathrm{Wi}$ & SFE Assistant & User Defined & Reorder & \\
\hline
\end{tabular}

Fig. 2: Defining components under study, including the solute and a set of solvents

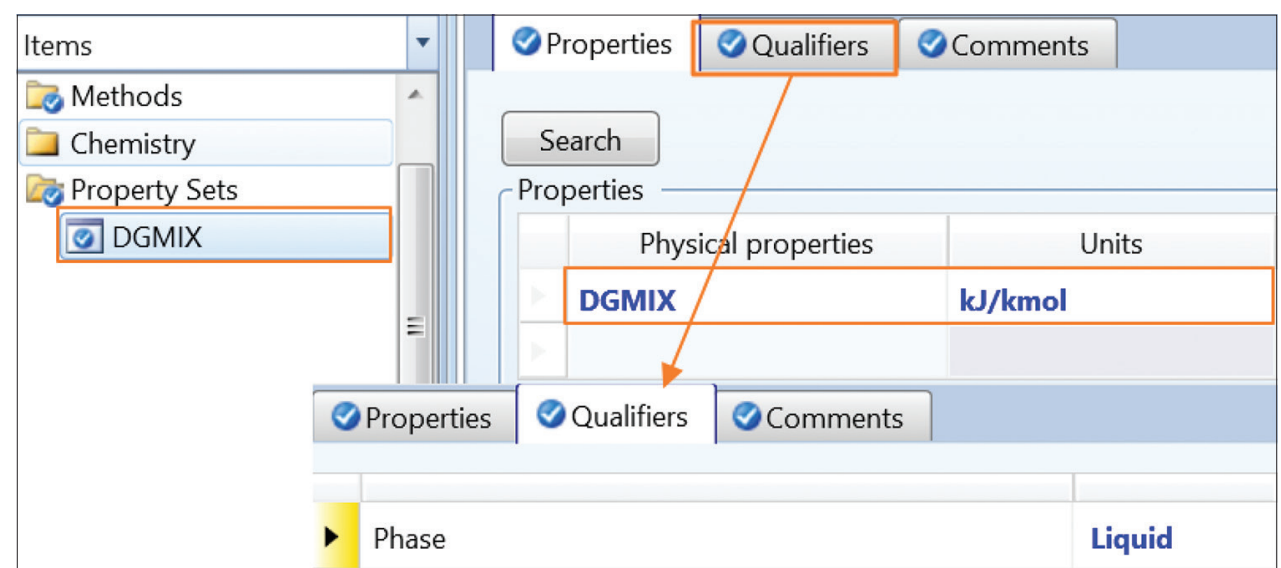

Fig. 3: Defining the property set which accounts for the molar Gibbs free energy of mixing for the outlet stream mixture 
signal. Given reliable thermodynamic data, sensible operating conditions, and rigorous equipment models, Aspen Plus enables us to run many tasks, like carrying out optimization case studies" [9].

I will show below in a chronological order the steps needed toward utilizing Aspen Plus powerful capability in carrying out optimization case studies for different pharmaceutical processes, in addition to traditional chemical processes.
The first step is to select the proper template. Since we deal with a drug, we will select the pharmaceutical template, as shown in Fig. 1.

The second step is to define the list of components to be used in our optimization case study. Fig. 2 shows such a list. The components are, acetylsalicylic acid (ASPIRIN), used as a solid solute, WATER, ACETONE, ETHANOL, and ethylene-glycol-mono-propyl-ether (PROPGLYC). Notice that, aspirin has been defined as "Conventional" not "Solid" type,

\begin{tabular}{|c|c|c|c|c|c|c|c|c|}
\hline \multirow{2}{*}{\begin{tabular}{|l} 
Properties \\
All Items
\end{tabular}} & \multirow{2}{*}{ s } & \multicolumn{4}{|c|}{ Methods $\times+$} & \multirow{2}{*}{ Comments } & & \\
\hline & & Global & \multicolumn{2}{|c|}{ Flowsheet Sections } & Referenced & & & \\
\hline \multirow{11}{*}{ 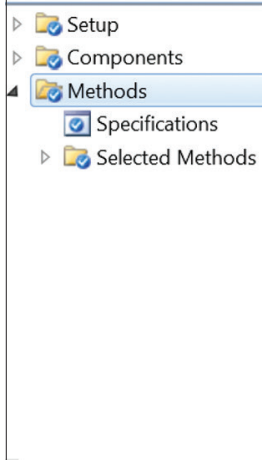 } & \multicolumn{5}{|c|}{ Property methods \& options } & $\begin{array}{l}\text { Comments } \\
\text { Method name }\end{array}$ & & \\
\hline & \multirow[t]{10}{*}{$\equiv$} & \multirow{3}{*}{\multicolumn{2}{|c|}{$\begin{array}{l}\text { Method filter } \\
\text { Base method } \\
\text { Henry components }\end{array}$}} & \multicolumn{2}{|l|}{ PHARMA } & \multirow{10}{*}{$\begin{array}{l}\text { NRTL } \\
\begin{array}{l}\square \text { Modify } \\
\text { Vapor EOS } \\
\text { Data set } \\
\text { Liquid gamma } \\
\text { Data set } \\
\text { Liquid molar enthalpy } \\
\text { Liquid molar volume } \\
\square \text { Heat of mixing }\end{array}\end{array}$} & \multicolumn{2}{|c|}{ Methods Assistan } \\
\hline & & & & NRTL & $\checkmark$ & & & \\
\hline & & & & & - & & & \\
\hline & & Petroleu & calculatio & n options & & & ESIG & 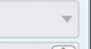 \\
\hline & & Free-wa & r method & STEAM-TA & $\checkmark$ & & & $1 \frac{\hat{v}}{\boldsymbol{v}}$ \\
\hline & & Water sc & ubility & 3 & $\checkmark$ & & GMRENON & \\
\hline & & & & & & & & $1 \hat{\hat{\imath}}$ \\
\hline & & - Electroly & e calculatio & n options & & & HLMX86 & $\nabla$ \\
\hline & & Chemist & $y$ ID & & - & & VLMX01 & \\
\hline & & $\nabla$ Use & ue compor & & & & & \\
\hline
\end{tabular}

Fig. 4: The selection of property method for assessing solution properties in hand

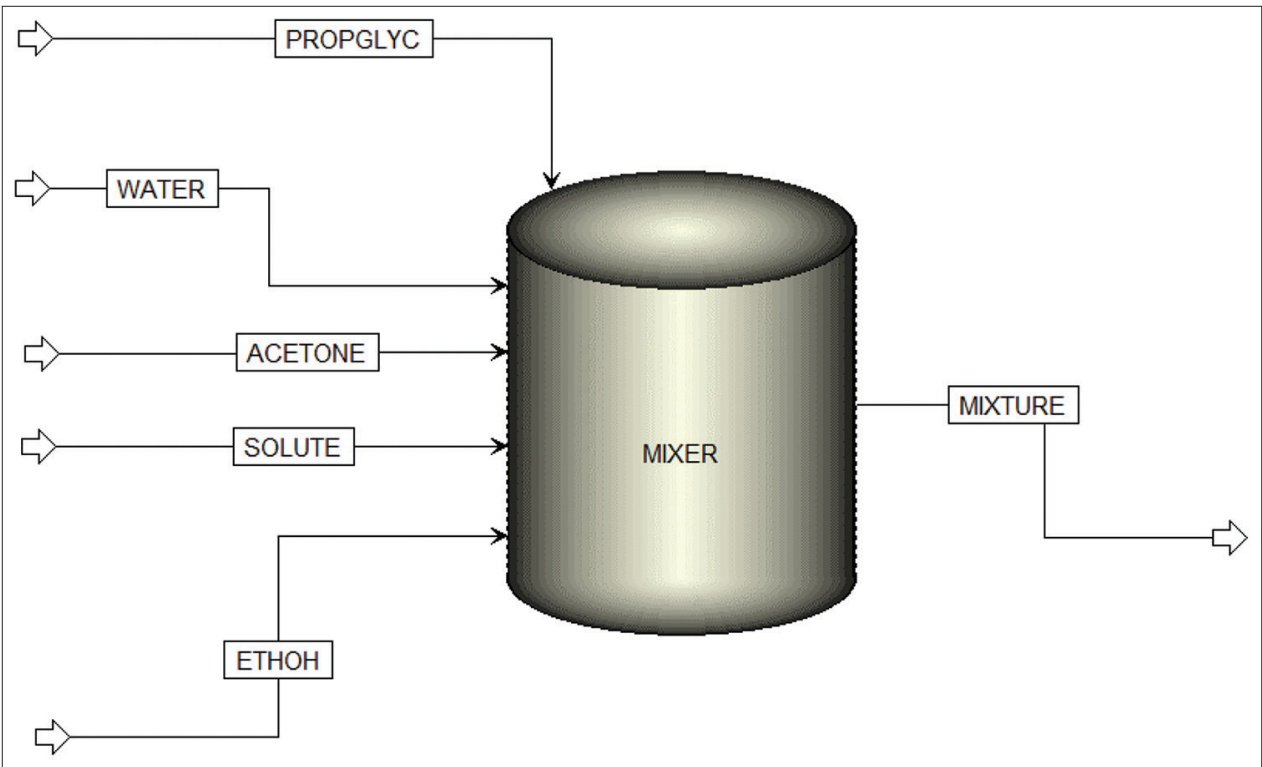

Fig. 5: A simplified process flow sheet for aspirin mixing

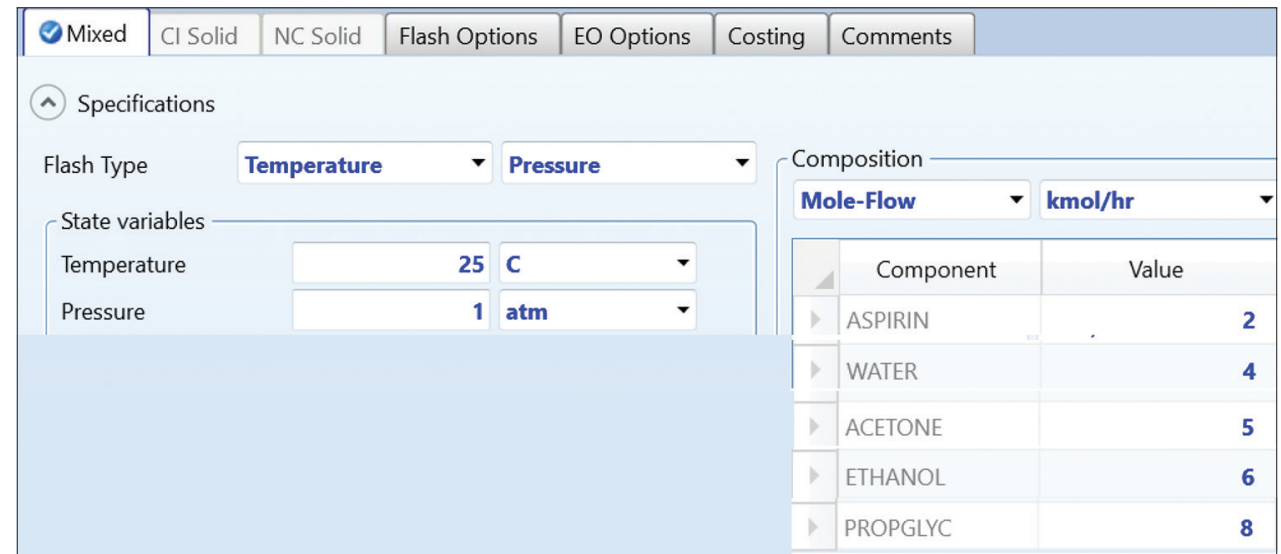

Fig. 6: A tentative initial value of flow rate for each feed stream. Such values will be modified under the optimization case study 
with the understanding that a conventional solid will be part of the aqueous medium (i.e., participates in phase equilibrium) and it has a well-defined molecular structure, according to Aspen Plus terminology. Organic solvents were chosen in light of the cited literature [3-5].

It is worth-mentioning here that Aspen Plus has some built-in databank drugs, such as ibuprofen, aspirin, and acetaminophen (paracetamol); nevertheless, if the drug is not defined as part of Aspen Plus databank, then it can be defined within Aspen Plus platform through its skeletal molecular editor and knowing some tiny little information about the drug itself, such as the melting point, boiling point, or density.

The third step is to define the property set which accounts for the outlet mixture property; namely, the molar Gibbs free energy of mixing, $\Delta \mathrm{G}_{\text {mix }}$ as shown in Fig. 3 . Such a property set will be utilized later in the optimization case study.

The fourth step is to select the property method, as shown in Fig. 4. In this case, the method filter is "PHARMA," which facilitates the selection of the property method. "Non-random Two-liquid (NRTL)", method is chosen as it has the capacity to deal with a very broad spectrum of components present in solutions.

After successfully carrying out the property analysis/setup step, we have to move from "Properties" to "Simulation" environment within Aspen Plus simulator.

The fifth step is to create a process flow sheet for handling the mixing process of paracetamol. Fig. 5 shows a simplified flow sheet for the aspirin mixing where it has five feed streams: One accounts for the solute; three of them for the set of organic solvents; and the last for water. Moreover, the product stream mixture can have aspirin as solubilized (liquid solution), undissolved (solid or crystal form), or both (S/L equilibrium phases). This process of mixing simply says that we start with pure individual raw materials and end up with a mixture or solution, which has, in general, molar solution properties that are functions of pressure, temperature, and molar composition of the constituting ingredients.

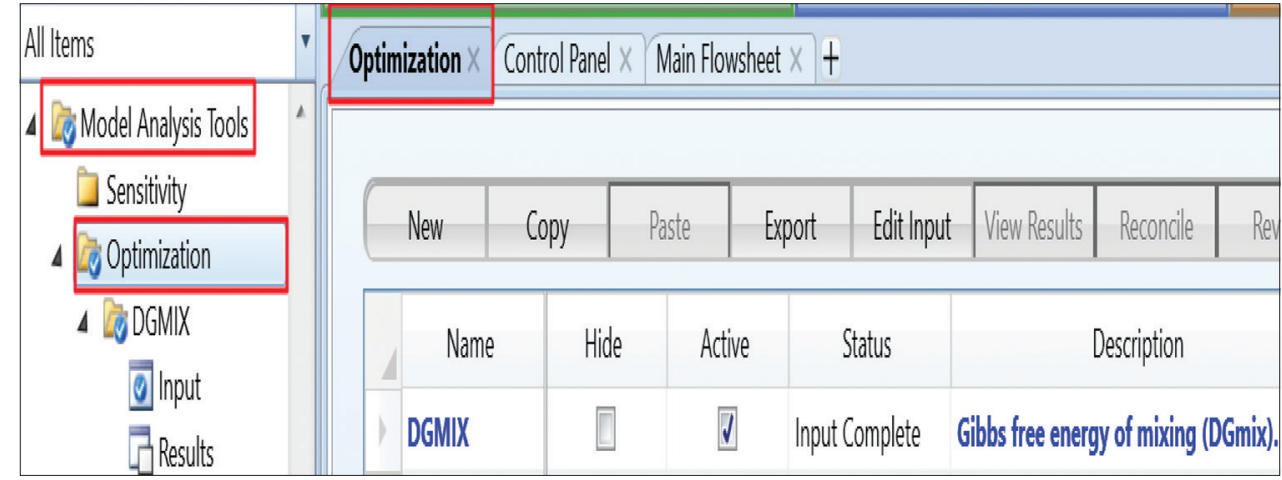

Fig. 7: Creation of an optimization case study with an objective function named DGMIX, the molar Gibbs free energy of mixing

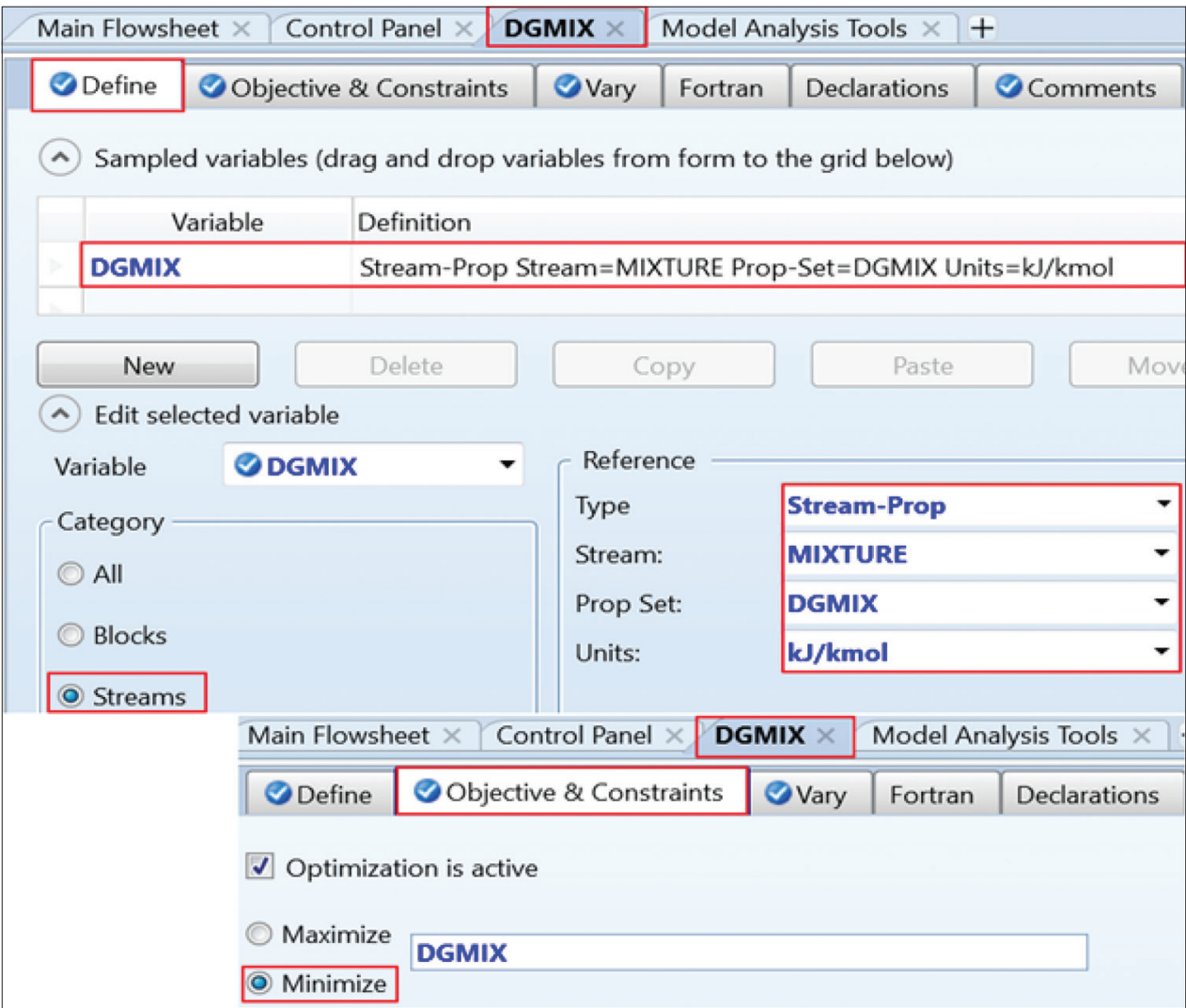

Fig. 8: Defining the objective function of optimization and whether to maximize or minimize 
The sixth step is to enter feed stream properties, as shown in Fig. 6. Such values of flow rate are tentative and they are subject to change or modification by the optimizer as shall be seen shortly. Notice that, Fig. 6 is a compilation of five separate feed folders.

The platform is now ready for using Aspen Plus "Optimization" tool under "Model Analysis Tools" feature.

The seventh step is to create an optimization case study. We will create one case study with the objective function named DGMIX, the molar Gibbs free energy of mixing for the output mixture stream, as shown in Fig. 7.

The eighth step is to define the attributes of the optimization case study. Fig. 8 shows how we define the objective function and then decide whether to maximize or minimize it on executing the optimization algorithm. In this case, DGMIX $\left(\Delta \mathrm{G}_{\text {mix }}\right)$ is defined, shown under "Define" tab, in light of the property set shown earlier in step \#3. The molar Gibbs free energy change on mixing will be minimized, shown under "Objective and Constraints" tab.
The ninth step is to pick up the manipulated variables which are thought to affect the already defined objective function, shown in step \#8. Fig. 9 shows the list of manipulated variables which represent the molar flow rates of each solvent, including water. The variation of each molar flow rate from 0 to $10 \mathrm{kmol} / \mathrm{h}$ will give the optimization algorithm the chance to search for the best composition which will give the minimum change in molar Gibbs free energy on mixing. Obviously, this will affect the final composition of the exit stream mixture. Notice that, we did not include the effect of temperature at this stage. Intuitively, the medium temperature affects both the stability and maximum solubility of an organic solute dissolved in a set of solvents, including water.

\section{RESULTS AND DISCUSSION}

Fig. 10 shows the summary of carrying out the optimization case study with $D_{\text {mix }}$ being the objective functions. The molar flow rate of each manipulated variable (Fig. 9) is shown at the final stage where the optimization algorithm stops at or converges to at least one local minimum ( $\mathrm{DG}_{\text {mix }}=-3248.7 \mathrm{~kJ} / \mathrm{kmol}$ ) if not an absolute global minimum as far as $D_{\text {mix }}$ changes as a function of the mole fractions: $X_{1}, X_{2}, \ldots, X_{n-1}$. The theme here is that given a molar flow rate of aspirin, the goal is to

\begin{tabular}{|c|c|c|c|c|c|c|c|c|c|c|}
\hline \multicolumn{11}{|c|}{ DGMIX-Input X } \\
\hline \multicolumn{2}{|c|}{ ODefine } & \multicolumn{2}{|c|}{ Oobjective \& Constraints } & OVary & OFortran & Dedarations & \multicolumn{4}{|l|}{$\theta$ Comments } \\
\hline \multicolumn{11}{|c|}{ (1) Manipulated variables (drag and drop variables from form to the grid below) } \\
\hline \multicolumn{2}{|c|}{ Variable } & Active & \multicolumn{5}{|c|}{ Manipulated variable } & Lower limit & Upper limit & Units \\
\hline$p$ & 1 & $\checkmark$ & \multicolumn{5}{|c|}{ Mole-Flow Stream=ACETONE Substream=MIXED Component=ACETONE } & 0 & 10 & $\mathrm{kmol} / \mathrm{hr}$ \\
\hline & 2 & $\checkmark$ & \multicolumn{5}{|c|}{ Mole-Flow Stream=ETHOH Substream=MIXED Component=ETHANOL } & 0 & 10 & $\mathrm{kmol} / \mathrm{hr}$ \\
\hline$p$ & 3 & $\checkmark$ & \multicolumn{5}{|c|}{ Mole-Flow Stream=PROPGLYC Substream=MIXED Component=PROPGLYC } & 0 & 10 & $\mathrm{kmol} / \mathrm{hr}$ \\
\hline & 4 & $\checkmark$ & \multicolumn{5}{|c|}{ Mole-Flow Stream=WATER Substream=MIXED Component=WATER } & 0 & 10 & $\mathrm{kmol} / \mathrm{hr}$ \\
\hline
\end{tabular}

Fig. 9: The manipulated variables which include the molar flow rate of each solvent, including water

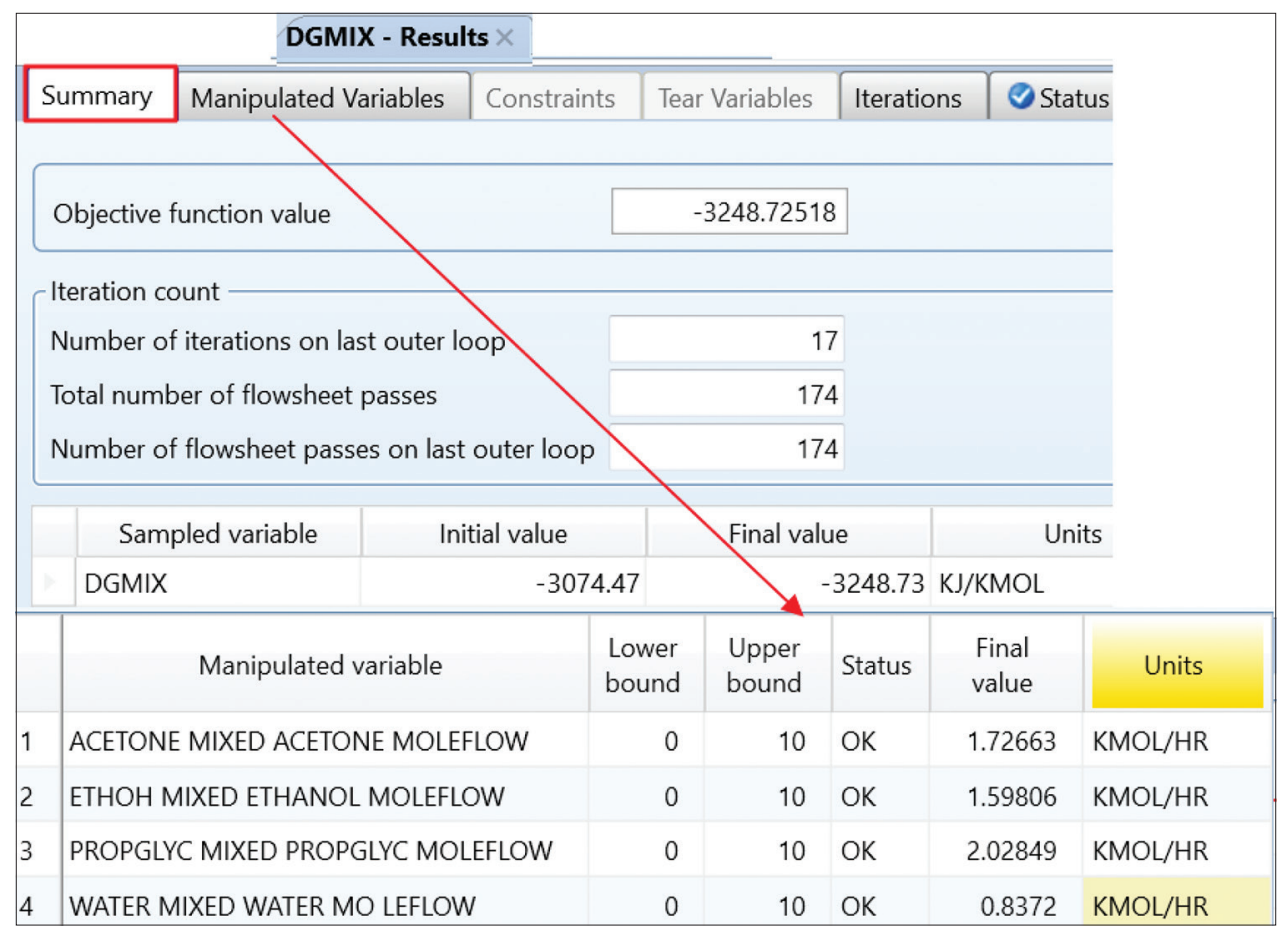

Fig. 10: The optimized inlet molar flow rates of solvents, based on the minimization of DGMIX 


\begin{tabular}{|c|c|c|}
\hline & \multirow{2}{*}{ Units } & \\
\hline & & MIXTURE \\
\hline - Mole Flows & kmol/hr & 8.19039 \\
\hline ASPIRIN & $\mathrm{kmol} / \mathrm{hr}$ & 2 \\
\hline WATER & $\mathrm{kmol} / \mathrm{hr}$ & 0.8372 \\
\hline ACETONE & $\mathrm{kmol} / \mathrm{hr}$ & 1.72663 \\
\hline ETHANOL & $\mathrm{kmol} / \mathrm{hr}$ & 1.59806 \\
\hline PROPGLYC & $\mathrm{kmol} / \mathrm{hr}$ & 2.02849 \\
\hline \multicolumn{3}{|l|}{ - Mole Fractions } \\
\hline ASPIRIN & & 0.244189 \\
\hline WATER & & 0.102217 \\
\hline ACETONE & & 0.210812 \\
\hline ETHANOL & & 0.195114 \\
\hline PROPGLYC & & 0.247667 \\
\hline + Mass Flows & $\mathbf{k g} / \mathbf{h r}$ & 760.573 \\
\hline \multicolumn{3}{|l|}{ - Mass Fractions } \\
\hline ASPIRIN & & 0.473749 \\
\hline WATER & & 0.0198303 \\
\hline ACETONE & & 0.131852 \\
\hline ETHANOL & & 0.0967971 \\
\hline PROPGLYC & & 0.277772 \\
\hline
\end{tabular}

Fig. 11: The optimized exit mixture molar and mass composition, based on the minimization of $D_{\text {MIX }}$

formulate the solution by varying the flow rate of each solvent involved in the solvation process.

Based on the minimization of $\Delta \mathrm{G}_{\text {mix }}$, the most stable formulated solution is the quinary mixture made of $24.42 \%$ aspirin, $10.22 \%$ water, $21.08 \%$ acetone, $19.51 \%$ ethanol, and 24.77 mole \% PROPGLYC, as shown in Fig. 11. Alternatively, the optimized mass fraction of the product (i.e. exit) stream is also shown in Fig. 11.

In a previous work [8], it was found that the solid powder of paracetamol mapped to the highest molar Gibbs free energy. Here, the minimization of molar Gibbs free energy of the solution, GMX, and maximization of solubility of aspirin in liquid solution both yielded to a pure solid of aspirin with zero molar flow rates of feed solvents (results are not shown here for the sake of brevity).

\section{CONCLUSIONS}

In general, Aspen Plus platform can be exploited to predict the optimum formulation of a given drug with different set of solvents and compositions. If the drug is not built-in as a data bank member, then it can be defined by Aspen Plus skeletal molecular editor with some little information about physical properties, such as melting point, boiling point, or density. Using the molar Gibbs free energy of mixing, $\Delta \mathrm{G}_{\text {mix }}$ as a criterion of solution thermodynamic stability, the most stable solution is the quinary mixture made of $24.42 \%$ aspirin, $10.22 \%$ water, $21.08 \%$ acetone, $19.51 \%$ ethanol, and 24.77 mole \% PROPGLYC.

\section{ACKNOWLEDGMENT}

The author acknowledges AspenTech (www.aspentech.com) as the licensor of the Aspen Plus software.

\section{AUTHORS' CONTRIBUTIONS}

Sole author; from A to Z: Inception; data analysis and presentation; and preparation of the manuscript.

\section{CONFLICTS OF INTEREST}

No conflicts of interest are present.

\section{FUNDING SOURCES}

Not applicable.

\section{REFERENCES}

1. Osborne C, Pack M. Aspirin. London, UK: Royal Society of Chemistry, Burlington House; 2003. Available from: https://www.edu.rsc.org/ download?ac=11241. [Last accessed on 2020 Jan 15].

2. Maia GD, Giulietti M. Solubility of acetylsalicylic acid in ethanol, acetone, propylene glycol, and 2-propanol. J Chem Eng Data 2008;53:256-8.

3. Huang Z, Chiew YC, Lu WD, Kawi S. Solubility of aspirin in supercritical carbon dioxide/alcohol mixtures. Fluid Phase Equilib 2005;237:9-15.

4. Mota FL, Queimada AJ, Pinho SP, Macedo EA. Solubility of druglike molecules in pure organic solvents with the CPA EoS. Fluid Phase 
Equilib 2011;303:62-70

5. Al-Malah KI. Aqueous solubility of a diatomic molecule as a function of its size \& electronegativity difference. J Mol Model 2011;17:325-31.

6. Al-Malah KI. Aqueous solubility of a simple (single-carbon) organic molecule as a function of its size \& dipole moment. J Mol Model 2011;17:1029-34.

7. Al-Malah K. Prediction of aqueous solubility of organic solvents as a function of selected molecular properties. J Pharm Drug Delivery Res 2012;1:1-7.

8. Al-Malah K. Optimization of drug solubility using aspen plus: Acetaminophen solubility, a case study. Int $\mathrm{J}$ Pharmacognosy 2018;5:724-31.

9. Al-Malah K. Aspen Plus: Chemical Engineering Applications. New York, USA: Wiley and Sons Inc.; 2016. 